\title{
Optimizing cancer cure dialog: an analysis of pancreatic cancer patients' views regarding survival and cure.
}

\author{
Avinoam Nevler \\ Thomas Jefferson University \\ Scott W. Keith \\ Thomas Jefferson University \\ Harish Lavu \\ Thomas Jefferson University \\ Theresa P. Yeo \\ Thomas Jefferson University \\ Sbipown phas Cannnaddatyonal works at: https://jdc.jefferson.edu/surgeryfp \\ Thomas Jefferson University \\ Part of the Oncology Commons, and the Surgery Commons \\ Let us know how access to this document benefits you
}

\section{Recommended Citation}

Nevler, Avinoam; Keith, Scott W.; Lavu, Harish; Yeo, Theresa P.; Cannaday, Shawnna; Yeo, Charles J.; and Winter, Jordan M., "Optimizing cancer cure dialog: an analysis of pancreatic cancer patients' views regarding survival and cure." (2019). Department of Surgery Faculty Papers. Paper 179.

https://jdc.jefferson.edu/surgeryfp/179

This Article is brought to you for free and open access by the Jefferson Digital Commons. The Jefferson Digital Commons is a service of Thomas Jefferson University's Center for Teaching and Learning (CTL). The Commons is a showcase for Jefferson books and journals, peer-reviewed scholarly publications, unique historical collections from the University archives, and teaching tools. The Jefferson Digital Commons allows researchers and interested readers anywhere in the world to learn about and keep up to date with Jefferson scholarship. This article has been accepted for inclusion in Department of Surgery Faculty Papers by an authorized administrator of the Jefferson Digital Commons. For more information, please contact: JeffersonDigitalCommons@jefferson.edu. 


\section{Authors}

Avinoam Nevler, Scott W. Keith, Harish Lavu, Theresa P. Yeo, Shawnna Cannaday, Charles J. Yeo, and Jordan M. Winter 


\title{
OPTIMIZING CANCER CURE DIALOGUE: AN ANALYSIS OF PANCREATIC CANCER
}

\section{PATIENTS' VIEWS REGARDING SURVIVAL AND CURE.}

\author{
Avinoam Nevler ${ }^{1,3} \uparrow, \mathrm{MD}$, Scott W. Keith ${ }^{2,3}, \mathrm{PhD}$, Harish Lavu ${ }^{1,3}, \mathrm{MD}$, FACS, \\ Theresa P. Yeo ${ }^{1,3}, \mathrm{PhD}, \mathrm{MPH}, \mathrm{MSN}$, Shawnna Cannaday $^{1,3}, \mathrm{CRNP}$, Charles J. \\ $\mathrm{Yeo}^{1,3}, \mathrm{MD}, \mathrm{FACS}$ and Jordan M. Winter ${ }^{4,5}, \mathrm{MD}, \mathrm{FACS}$.
}

${ }^{1}$ Departments of Surgery and the Jefferson Pancreas, Biliary and Related Cancer Center; ${ }^{2}$ Department of Pharmacology and Experimental Therapeutics, Division of Biostatistics; ${ }^{3}$ Sidney Kimmel Medical College and Sidney Kimmel Cancer Center, Thomas Jefferson University, Philadelphia, PA, United States; ${ }^{4}$ Department of Surgery and Division of Surgical Oncology, University Hospitals Cleveland Medical Center, Cleveland, OH, United States. ${ }^{5}$ School of Medicine, Case Western Reserve University, Cleveland, OH, United States

Running Title: PDAC Patients’ Views Regarding Cancer Survival.

Keywords: Cancer survival, pancreatic cancer, pancreatic ductal adenocarcinoma, cancer cure.

COI Statement: The authors declare no potential conflicts of interest.

$\nmid$ Corresponding author: Department of Surgery, Thomas Jefferson University. Philadelphia, PA. 1015 Walnut Street, 611 Curtis building, Philadelphia, PA, 19107. Phone: 215-955-0685. Email: avinoam.nevler@jefferson.edu 


\begin{abstract}
Background: Pancreatic ductal adenocarcinoma (PDA) is a highly lethal cancer. Clinicians commonly refer to surgical therapy as resection with curative intent. However, PDA cure rates after resection remain unknown and the definition of cure remains vague. We investigated how patients (the majority undergoing resection), family members, and clinicians understand the concept of cure, to better inform discussions with patients regarding PDA prognosis.
\end{abstract}

Methods: In a prospective survey, cohorts were asked to indicate the best definition of cure from three choices: 5-year survival endpoint (typically used in the literature); a biological endpoint without biochemical or radiographic signs of disease (similar to the NCI definition); or a practical endpoint where life span approximates similarly aged patients without PDA. Fleiss' kappa statistic was calculated to measure inter-rater agreement.

Results: Patients, family members and health care professionals $(\mathrm{N}=200)$ agreed that renormalization of life expectancy was the preferred definition of cure in the context of pancreatic cancer. Inter-rater agreement was highest for the patient and family member groups (Fleiss' Kappa 0.27 and 0.40 respectively. $\mathrm{P}<0.001$ ), while variability was observed between health care professionals (Fleiss' Kappa 0.11, $\mathrm{P}<0.001$ ).

Conclusions: In all groups surveyed, the probability for a normal life expectancy is the preferred long-term metric in patients with early-staged pancreatic cancer. Renormalization of life expectancy appears to be an important therapy goal for PDA patients and it is advisable to address this topic during clinical discussions. 


\section{INTRODUCTION}

Pancreatic cancer is currently the third leading cause of cancer death in the United States $^{1}$, and is expected to become second to lung cancer within the next decade. The disease is highly lethal with an overall 5-year survival of only $9 \%{ }^{1-3}$. Patients with advanced disease have five-year survival rates of just $3 \%{ }^{2,3}$. Approximately $20 \%$ of patients with PDA have localized and resectable disease at diagnosis and this group has the best long-term outcome. In this resected subgroup, five-year survival rates are $15-18 \%{ }^{4-6}$. In fact, patients undergoing resection for PDA are the only ones believed to have a realistic chance for cure.

A cancer cure is the ultimate hope for every patient. Clinicians may occasionally suggest a possibility of this desired outcome during preoperative discussions. In some cases, clinicians may even suggest that a cure has been achieved, particularly after a long follow-up interval. However, to our knowledge, there has never been an attempt to quantify cure rates after PDA resection. To date, the five-year survival rate has been the gold standard definition for long-term outcome in this cohort. Importantly, a small number of studies with longer follow-up clearly indicate that recurrences and cancer-specific mortality occur beyond this 5 -year time point ${ }^{6}$. Moreover, while conventional clinical survival endpoints (cancer-specific mortality, disease free survival, etc. $)^{7}$ are useful for research studies and clinical trials to benchmark progress, they may have less meaning for patients and their families who are unaccustomed to processing statistical information.

The NCI provides the following statement on cancer cure ${ }^{8}$ :

"Cure means that there are no traces of your cancer after treatment and the cancer will never come back...If you remain in complete remission for 5 years or more, some doctors may say that you are cured. Still, some cancer cells can remain in your body for many years after treatment. 
These cells may cause the cancer to come back one day. For cancers that return, most do so within the first 5 years after treatment. But, there is a chance that cancer will come back later. For this reason, doctors cannot say for sure that you are cured. The most they can say is that there are no signs of cancer at this time."

Not only is a cancer cure impossible to determine clinically, but application of this definition assumes that patients desire, above all else, to have their disease eradicated and for it to never return. But what if patients die prematurely for other reasons, such as from complications of their surgery or chemotherapy? Such an outcome is clearly less desirable than a biologic cure. On the other hand, a 'healthy' normal life span may be a more appealing endpoint, even if there remains radiologic or biochemical evidence of indolent, non-active disease.

In population-based biostatistics, cure is defined as the normalization of the mortality rate in the affected population back to the same level as in the general population ${ }^{9}$. Several studies have looked at this definition in an attempt to estimate cancer cure rates ${ }^{10,11}$. However, the use of this definition is still mainly limited to cross-sectional population based studies with minimal use in the clinical setting. Determining the best survival endpoint and definition of cure has important implications for surveillance strategies, as well as for discussions between clinicians and patients. Thus, we sought to determine a practical definition of cure with objective, quantifiable end-points, consistent with patients' and providers' perceptions of the endpoint and their goals of treatment.

\section{MATERIALS AND METHODS}

A prospective, questionnaire-based study was designed to assess stakeholder perspectives on curative therapy as well as their desired goals of treatment (Supplementary Figure 1). The study was performed between November 2016 and May 2017. Participants were approached during the 
annual pancreatic cancer and related diseases symposium (November 2016, Thomas Jefferson University, Philadelphia, PA) and during regular outpatient clinic visits. Surveyed individuals included patients, their family members, and clinicians/cancer researchers (i.e, senior surgeons, oncologists, clinical researchers, and translational pancreatic cancer researchers). Most patients included in the study had previously undergone curative intent pancreatic resection; some had already experienced a cancer recurrence. Gender, age and study group (1: Patients, 2: Family Members and 3: Clinicians/Clinical pancreatic cancer researchers) were recorded. For individuals in group 1 (patients), participants were also asked to indicate whether a pancreatectomy was performed. All participants were asked to review three possible scenarios, and select the one which most closely met their definition of a pancreatic cancer cure (See Supplementary Figure 1):

A. Surviving for 5 years (i.e., the literature benchmark).

B. Having normal laboratory and imaging test results for the rest of your life (i.e., scientific definition, an approximation of the NCI statement above).

C. Living a normal life span, similar to an age-matched person without pancreatic cancer (i.e., a practical definition).

Participants were also asked to rate these statements according to how useful each of the metrics were in their view, as compared to the other choices (from the most informative endpoint to the least informative). Between-group analysis was then performed using Wilcoxon's ranked test. Within-group determination of internal agreement was performed using $\mathrm{R}^{12}$ ( $\mathrm{R}$ version 3.3.2, 2016, The R foundation for statistical computing) with the raters package ${ }^{13}$ for Fleiss' Kappa test. P values $\leq 0.05$ were considered as statistically significant. Questionnaires were indexed by 
a serial number, and no patient identifiable data were recorded. The study was approved by the Thomas Jefferson University Institutional Review Board.

\section{RESULTS}

\section{Defining pancreatic cancer cure}

A total of 350 questionnaires were prepared and assigned form identifiers. Of these 200 questionnaires were returned for analysis (57\%). Cohort characteristics and question response rates are provided in Tables 1-2. Average question response rates were $>95 \%$ across each subgroup. Normal life expectancy was the preferred definition for pancreatic cancer cure (chosen by $67 \%$ of the participants, Figure $1 \mathrm{~A}, \mathrm{P}<0.01$ ) in the whole cohort, as well as for each questioned sub-group (Figure 1B). Interestingly, while the five year survival endpoint is the standard survival endpoint used in the literature, respondents considered this definition to be the least meaningful out of the provided choices. Only $5 \%$ of respondents preferred this metric. The response profile was only slightly different in the researcher/clinician subgroup compared to patient and family member subgroups (Figure $1 \mathrm{~B}, \mathrm{P}=0.1$ and $\mathrm{P}=0.025$, Fisher's exact test), although overall trends were similar.

The questionnaire's second question asked for patients to rank the three possible definitions based on their subjective informative value. Consistent with the previous question, normal life expectancy was selected as the most informative metric (ranked as most important by $70 \%$ of the participants, $\mathrm{P}<0.01$, Figure $2 \mathrm{~A}$ ), as well as in subgroup analyses (Figure $2 \mathrm{~B}-\mathrm{D})$. A high level of inter-group agreement was found in both the patient and patient family member groups $(\mathrm{k}=0.25$ and $\mathrm{k}=0.40$, respectively, $\mathrm{P}<0.01)$. In contrast, the internal agreement levels in the researcher/clinician subgroup were lower $(\mathrm{k}=0.09, \mathrm{P}<0.01)$. Thus, the most knowledgeable individuals had the greatest disagreement. 


\section{DISCUSSION}

Cure is the desired treatment goal of early, or localized, cancer. This principal is even conveyed in our own Sidney Kimmel Cancer Center's motto: “Until every cancer is cured."14. It therefore seems reasonable to design studies that attempt to capture this important metric, particularly since it is acknowledged by patients, family members, and clinicians, during discussions of prognosis. Unfortunately, the biologic definition offered by the NCI ("that there are no traces of your cancer after treatment and the cancer will never come back.”) cannot be definitively tracked using currently available cancer surveillance technologies.

Clear, compassionate communication of treatment goals, treatment chances and expected survival is a challenge, further complicated but a multitude of different survival metrics and conflicting viewpoint and perceptions. In this study, we offer an alternative definition that can potentially be quantified and tracked. Moreover, the proposed definition is consistent with the endpoints desired by the principal stakeholders, including patients, family members, and health care professionals. Individuals completing the study survey considered three possible definitions of PDA cure: the standard published outcome metric (5-year survival), a biologic metric similar in intent to a scientific definition proposed by the NCI (i.e., any detectable trace of disease), and a practical definition (where life span is renormalized). Each of these definitions has associated advantages and disadvantages for use as a metric (Table 3). For instance, the five-year survival milestone is frequently used in the surgical oncology literature as a primary outcome measure and is simple to measure. However, the endpoint ignores the fact that late recurrences occur. Strikingly, the present study revealed that this oft quoted cancer survival endpoint was the least meaningful out of the survey options offered to study participants. The second definition considers biologic aspects of cure, and fits best with the NCI definition. However, there is no an 
available test that can definitively rule out the presence of microscopic and sub-clinical PDA, diminishing its practical utility. The definition is purely conceptual. In the real world, PDA recurrences are detected using imaging studies and serum tumor markers with sensitivities around $90 \%{ }^{15-17}$. Assays that test for circulating tumor cells (CTC) ${ }^{18}$ have even lower sensitivities (47-68\%) ${ }^{19,20}$. Additionally, in other diseases like breast cancer, patients frequently harbor sub-clinical bone marrow metastases for decades ${ }^{21-24}$ without any impact on quality of life or longevity. This finding suggests that a biologic definition would not be practically relevant for all patients, especially elderly individuals with other comorbidities. The third definition has been under-utilized in the cancer literature, but is recommended by the European Conference on Survivors and Chronic Cancer ${ }^{25}$. A determination of 'normal life expectancy' can be extracted from general population statistical life tables (for example, life tables from the Social Security Administration). In fact, all stakeholders in the present study highlighted renormalization of life expectancy as the preferred definition of PDA cure. From a practical standpoint, a patient living a normal life span would be considered to be cured by most stakeholders, even if a test were able to detect subclinical and microscopic disease. While biologically speaking, the patient in this case would not have been considered as cured, in terms of cancer treatment goals, most stakeholders in our study preferred that endpoint to the standardly used endpoint of 5 years of cancer free survivorship.

The manner in which prognosis is conveyed to patients and family members can have major emotional and social consequences. For instance, the term "cancer survivorship" is a stressful reminder for some patients that a threat of recurrence looms ${ }^{26}$. For others, 'survivorship' offers a sense of personal growth and achievement. Terms such as 'cured', 'healed', and 
remission are more optimistic ${ }^{25}$, but their intended meaning can be misinterpreted. Indeed, this study reveals the range of possible interpretations of "cure" in the context of pancreatic cancer.

For PDA, the actual cure rate has never been effectively quantified. Even "early" PDA lesions ( $<2 \mathrm{~cm}$ invasive component) have a tendency to spread and recur more frequently than other similarly sized cancer types ${ }^{27}$. Long-term survival studies reveal that patients with resected PDA reach the 5-year time point roughly $20 \%$ of the time ${ }^{6,28-30}$; thus, actual cure rates must be lower than this number. Studies with longer follow-up intervals report that PDA recurrences occur more than 10 years after resection ${ }^{6}$. In fact, conditional survival analyses show that patients who survive five years after resection still have an excess mortality rate compared to the general population ${ }^{31}$.

\section{Limiting and biasing factors}

Several biasing factors in our study limit the interpretation and generalization of the results. First, this is a single center study. In addition, the vast majority of patient participants underwent a pancreatic resection (>92\%). Most of the patient participants had relatively early and surgically managed pancreatic tumors at presentation. Therefore, perspectives of patients who presented with advanced or metastatic disease are not well represented in this survey. While we have tried to minimize misinformation bias by verbally explaining each of the proposed definitions during the survey, it is possible that some of the patients misunderstood the questions or believed some definitions to be inclusive of the other ones. The cross-sectional design of our study at a single time point also does not consider individual shifts in perspective or opinion over time. Also, we do not evaluate perceptions of cure for other tumor types. Finally, none of these definitions precisely and accurately describe the scientific definition of cure. Rather, they describe patients' perceptions of cure with respect to their own conditions. 


\section{CONCLUSIONS}

Patient-Clinician communication regarding pancreatic cancer cure is complex and prone to misperception regarding the informative value of different survival statistics. A normal life expectancy was the most important long-term outcome metric according to patients with earlystaged pancreatic cancer. Clinicians should be mindful in discussion of prognosis that actual PDA cure rates have not been rigorously determined and remain unknown. Further, the meaning of cure may not be fully understood by patients and family members. Importantly, the preferred definition identified in this study - renormalization of anticipated life expectancy - is actually estimable. This outcome can be calculated through comparisons of PDA survival data and data from actuarial life tables of age-matched individuals in the general population. Based on these results, we submit that this new outcome metric (i.e., renormalization of life expectancy) should be determined for PDA patients, and serve as a new benchmark for scientific progress, with the ultimate research goal to improve cure rates. Ongoing work in this area by our group is intended to meet this objective.

\section{Compliance with ethical standards}

Conflict of interest: The authors declare that they have no conflicts of interest.

The authors have full control of primary data and would allow review of the data if requested.

Ethical approval: The study was performed in accordance with the ethical standards of the institutional review board and with the 1964 Helsinki declaration and its later amendments. 
References

1. American Cancer Society. American Cancer Society (ACS) Facts and Figures 2019. 2019; https://www.cancer.org/research/cancer-facts-statistics/all-cancer-facts-figures/cancer-factsfigures-2019.html.

2. Siegel RL, Miller KD, Jemal A. Cancer statistics, 2017. CA: A Cancer Journal for Clinicians. 2017;67(1):7-30.

3. Siegel RL, Miller KD, Jemal A. Cancer statistics, 2018. CA Cancer J Clin. Jan 2018;68(1):7-30.

4. Winter JM, Cameron JL, Campbell KA, et al. 1423 pancreaticoduodenectomies for pancreatic cancer: A single-institution experience. J Gastrointest Surg. Nov 2006;10(9):1199-1210; discussion 1210-1191.

5. Brennan MF, Kattan MW, Klimstra D, et al. Prognostic nomogram for patients undergoing resection for adenocarcinoma of the pancreas. Ann Surg. Aug 2004;240(2):293-298.

6. Ferrone CR, Pieretti-Vanmarcke R, Bloom JP, et al. Pancreatic ductal adenocarcinoma: long-term survival does not equal cure. Surgery. Sep 2012;152(3 Suppl 1):S43-49.

7. Mariotto AB, Noone AM, Howlader N, et al. Cancer survival: an overview of measures, uses, and interpretation. J Natl Cancer Inst Monogr. Nov 2014;2014(49):145-186.

8. NIH-NCI. Understanding Cancer Prognosis https://www.cancer.gov/about-cancer/diagnosisstaging/prognosis.

9. Lambert PC, Thompson JR, Weston CL, et al. Estimating and modeling the cure fraction in population-based cancer survival analysis. Biostatistics. Jul 2007;8(3):576-594.

10. Dal Maso L, Guzzinati S, Buzzoni C, et al. Long-term survival, prevalence, and cure of cancer: a population-based estimation for 818902 Italian patients and 26 cancer types. Ann Oncol. Nov 2014;25(11):2251-2260.

11. Spolverato G, Vitale A, Cucchetti A, et al. Can hepatic resection provide a long-term cure for patients with intrahepatic cholangiocarcinoma? Cancer. Nov 15 2015;121(22):3998-4006.

12. Core-Team R. R: A language and environment for statistical computing. 2016; https://www.Rproject.org/.

13. Daniele Giardiello, Piero Quatto, Enrico Ripamonti, et al. raters: A Modification of Fleiss' Kappa in Case of Nominal and Ordinal Variables. 2014; https://cran.rproject.org/web/packages/raters/index.html.

14. Center" SKC. Sidney Kimmel Cancer Center - Thomas Jefferson University. http://www.kimmelcancercenter.org/cancer-center.html.

15. Fong ZV, Tan WP, Lavu H, et al. Preoperative imaging for resectable periampullary cancer: clinicopathologic implications of reported radiographic findings. J Gastrointest Surg. Jun 2013;17(6):1098-1106.

16. Narimatsu H, Iwasaki H, Nakayama F, et al. Lewis and secretor gene dosages affect CA19-9 and DU-PAN-2 serum levels in normal individuals and colorectal cancer patients. Cancer Res. Feb 1 1998;58(3):512-518.

17. Tempero MA, Uchida E, Takasaki H, et al. Relationship of carbohydrate antigen 19-9 and Lewis antigens in pancreatic cancer. Cancer Res. Oct 15 1987;47(20):5501-5503.

18. Ankeny JS, Court CM, Hou S, et al. Circulating tumour cells as a biomarker for diagnosis and staging in pancreatic cancer. Br J Cancer. Jun 14 2016;114(12):1367-1375.

19. de Albuquerque A, Kubisch I, Breier G, et al. Multimarker gene analysis of circulating tumor cells in pancreatic cancer patients: a feasibility study. Oncology. 2012;82(1):3-10. 
20. Zhang Y, Wang F, Ning N, et al. Patterns of circulating tumor cells identified by CEP8, CK and CD45 in pancreatic cancer. International journal of cancer. Journal international du cancer. Mar 1 2015;136(5):1228-1233.

21. Early Breast Cancer Trialists' Collaborative G. Effects of chemotherapy and hormonal therapy for early breast cancer on recurrence and 15-year survival: an overview of the randomised trials. Lancet. May 14-20 2005;365(9472):1687-1717.

22. Karrison TG, Ferguson DJ, Meier P. Dormancy of mammary carcinoma after mastectomy. J Natl Cancer Inst. Jan 6 1999;91(1):80-85.

23. Kim RS, Avivar-Valderas A, Estrada Y, et al. Dormancy signatures and metastasis in estrogen receptor positive and negative breast cancer. PLoS One. 2012;7(4):e35569.

24. Zhang XH, Giuliano M, Trivedi MV, et al. Metastasis dormancy in estrogen receptor-positive breast cancer. Clin Cancer Res. Dec 1 2013;19(23):6389-6397.

25. Tralongo P, Maso LD, Surbone A, et al. Use of the word "cured" for cancer patientsimplications for patients and physicians: the Siracusa charter. Current Oncology. 2015;22(1):e38e40.

26. Khan NF, Harrison S, Rose PW, et al. Interpretation and acceptance of the term 'cancer survivor': a United Kingdom-based qualitative study. Eur J Cancer Care (Engl). Mar 2012;21(2):177-186.

27. Winter JM, Jiang W, Basturk O, et al. Recurrence and Survival After Resection of Small Intraductal Papillary Mucinous Neoplasm-associated Carcinomas ( $</=20-\mathrm{mm}$ Invasive Component): A Multi-institutional Analysis. Ann Surg. Apr 2016;263(4):793-801.

28. Dusch N, Weiss C, Strobel P, et al. Factors predicting long-term survival following pancreatic resection for ductal adenocarcinoma of the pancreas: 40 years of experience. J Gastrointest Surg. Apr 2014;18(4):674-681.

29. Schnelldorfer T, Ware AL, Sarr MG, et al. Long-term survival after pancreatoduodenectomy for pancreatic adenocarcinoma: is cure possible? Ann Surg. Mar 2008;247(3):456-462.

30. Riall TS, Cameron JL, Lillemoe KD, et al. Resected periampullary adenocarcinoma: 5-year survivors and their 6- to 10-year follow-up. Surgery. Nov 2006;140(5):764-772.

31. Baade PD, Youlden DR, Chambers SK. When do I know I am cured? Using conditional estimates to provide better information about cancer survival prospects. Med J Aust. Jan 17 2011;194(2):73-77. 


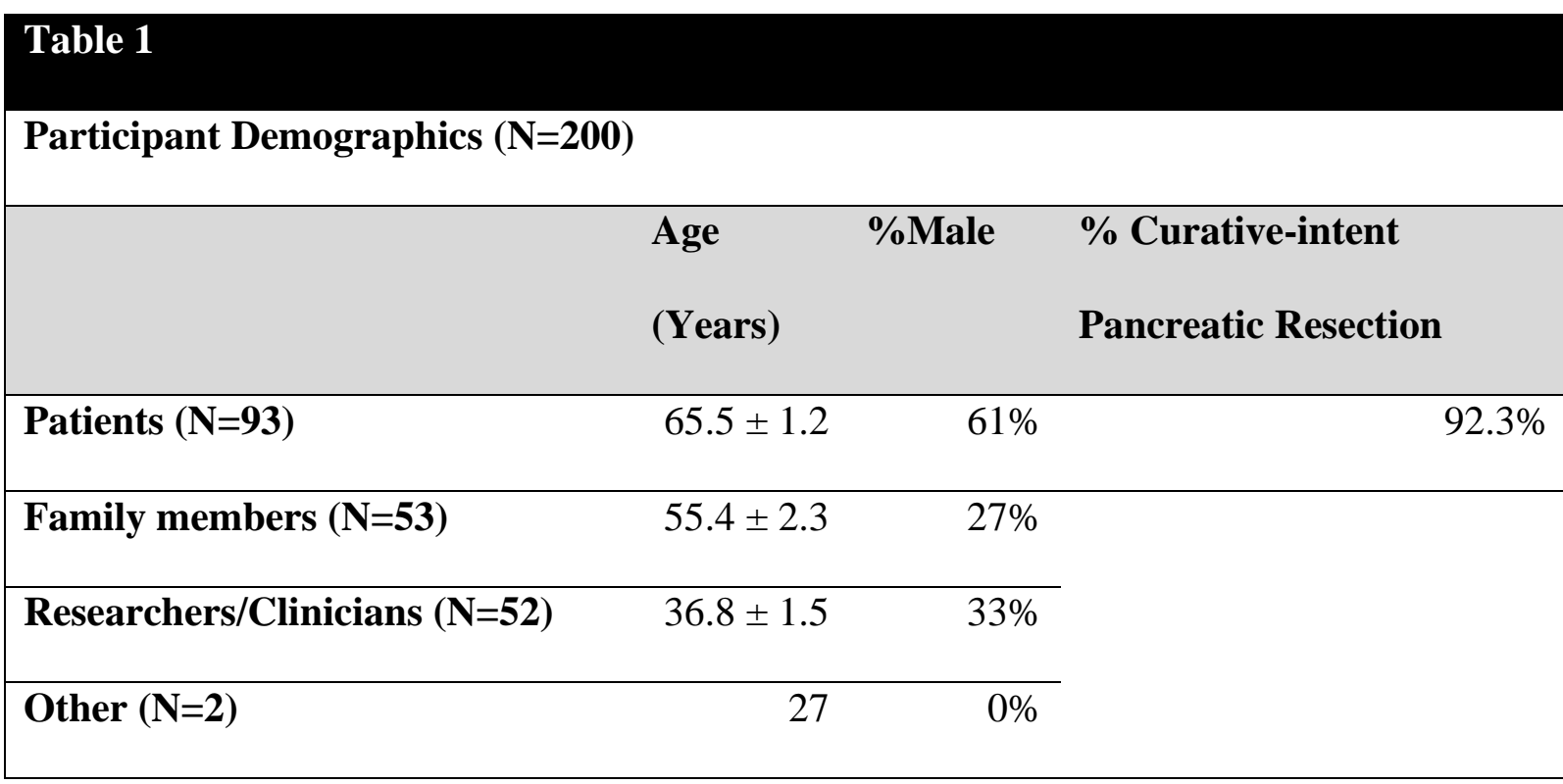

Table 1. Participant demographics (Mean \pm Std.Er). 


\begin{tabular}{|lll|}
\hline & & \\
& Item\#1* & Item\#2* \\
& Best Cure Definition & Perceived Informative Value \\
\hline Patients (N=93) & $93(100 \%)$ & $87(94 \%)$ \\
\hline Family members (N=53) & $49(92 \%)$ & $52(98 \%)$ \\
\hline Researchers/Clinicians $(\mathbf{N = 5 2 )}$ & $52(100 \%)$ & $52(100 \%)$ \\
\hline Other (N=2) & $1(50 \%)$ & $1(50 \%)$ \\
\hline Missing Data & 5 & 8 \\
\hline Total & $\mathbf{2 0 0}$ & $\mathbf{2 0 0}$ \\
\hline
\end{tabular}

Table 2. Questionnaire item completion rates (in parenthesis, relative item completion rates in percentages). * See Supplementary Figure 1. 


\begin{tabular}{|c|c|c|c|}
\hline $\begin{array}{l}\text { Endpoint } \\
\text { Category }\end{array}$ & Definition & Advantages of use & Limitations of use \\
\hline $\begin{array}{l}\text { Standard } \\
\text { reported } \\
\text { endpoint }\end{array}$ & $\begin{array}{l}\text { Surviving for } 5 \\
\text { years. }\end{array}$ & $\begin{array}{l}\text { - Easy to measure and interpret in } \\
\text { clinical studies } \\
\text { - Easy to compare across various } \\
\text { groups and cancers. } \\
\text { - Requires a defined short follow } \\
\text { up period }\end{array}$ & $\begin{array}{l}\text { - Uninformative for pathologies } \\
\text { with high survival rate } \\
\text { - Generalized and not patient } \\
\text { specific } \\
\text { - Does not capture dormant } \\
\text { disease or delayed recurrences }\end{array}$ \\
\hline $\begin{array}{l}\text { Biologic } \\
\text { definition }\end{array}$ & $\begin{array}{l}\text { Having normal } \\
\text { laboratory and } \\
\text { imaging test results } \\
\text { for the rest of your } \\
\text { life. }\end{array}$ & $\begin{array}{l}\text { - Easy to comprehend by non- } \\
\text { health professionals. } \\
\text { • Closest measurable scientific } \\
\text { endpoint for 'cure' }\end{array}$ & $\begin{array}{l}\text { - Requires very long term follow- } \\
\text { up } \\
\text { - Over-interprets dormant and } \\
\text { clinically irrelevant disease } \\
\text { - Does not necessarily correlate } \\
\text { with survival } \\
\text { - Difficult to compare across } \\
\text { various groups and cancers. }\end{array}$ \\
\hline $\begin{array}{l}\text { Practical } \\
\text { definition }\end{array}$ & $\begin{array}{l}\text { Living a normal life } \\
\text { expectancy, similar } \\
\text { to a person without } \\
\text { pancreatic cancer }\end{array}$ & $\begin{array}{l}\text { - Patient specific } \\
\text { - Easy to comprehend by non- } \\
\text { health professionals. } \\
\text { - Requires a defined follow up } \\
\text { period (varies between patients). }\end{array}$ & $\begin{array}{l}\text { - Allows for existence of active or } \\
\text { dormant disease } \\
\text { - Complicate clinical study design } \\
\text { (requires individual age-adjusted } \\
\text { follow-up durations for patients) }\end{array}$ \\
\hline
\end{tabular}




\begin{tabular}{|l|l|l|l|}
\hline & $\begin{array}{l}\bullet \text { Easy to compare across various } \\
\text { groups and cancers. }\end{array}$ & \\
\hline
\end{tabular}

Table 3. Comparison of various survival endpoints with possible advantages and limitations of use. 
Figure Legends

Figure 1. (A) Participants' answer distribution for definition of endpoint of cure of pancreatic

cancer ( $\mathrm{P}<0.01, \chi^{2}$ test). (B) Sub-population comparison of participants' answer distribution for definition of endpoint of cure of pancreatic cancer $\left(\chi^{2}\right.$ test).

Figure 2. Overall and Sub-population comparison of participants' ranking of three proposed long-term endpoint metrics for their informative value in pancreatic cancer (Fleiss' kappa analysis).

Supplementary Figure 1. Participant Questionnaire 
Figure 1A

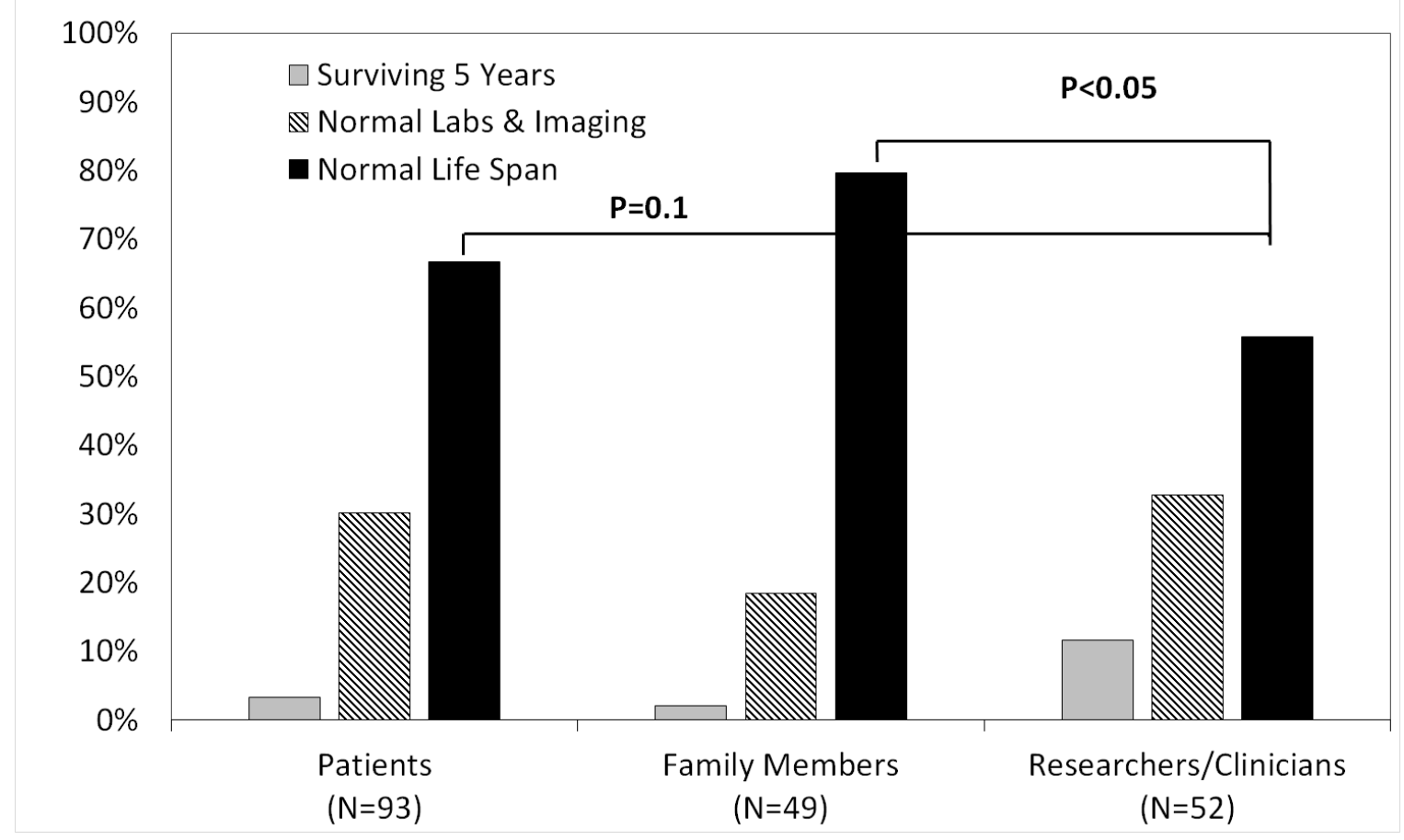

Figure 1B

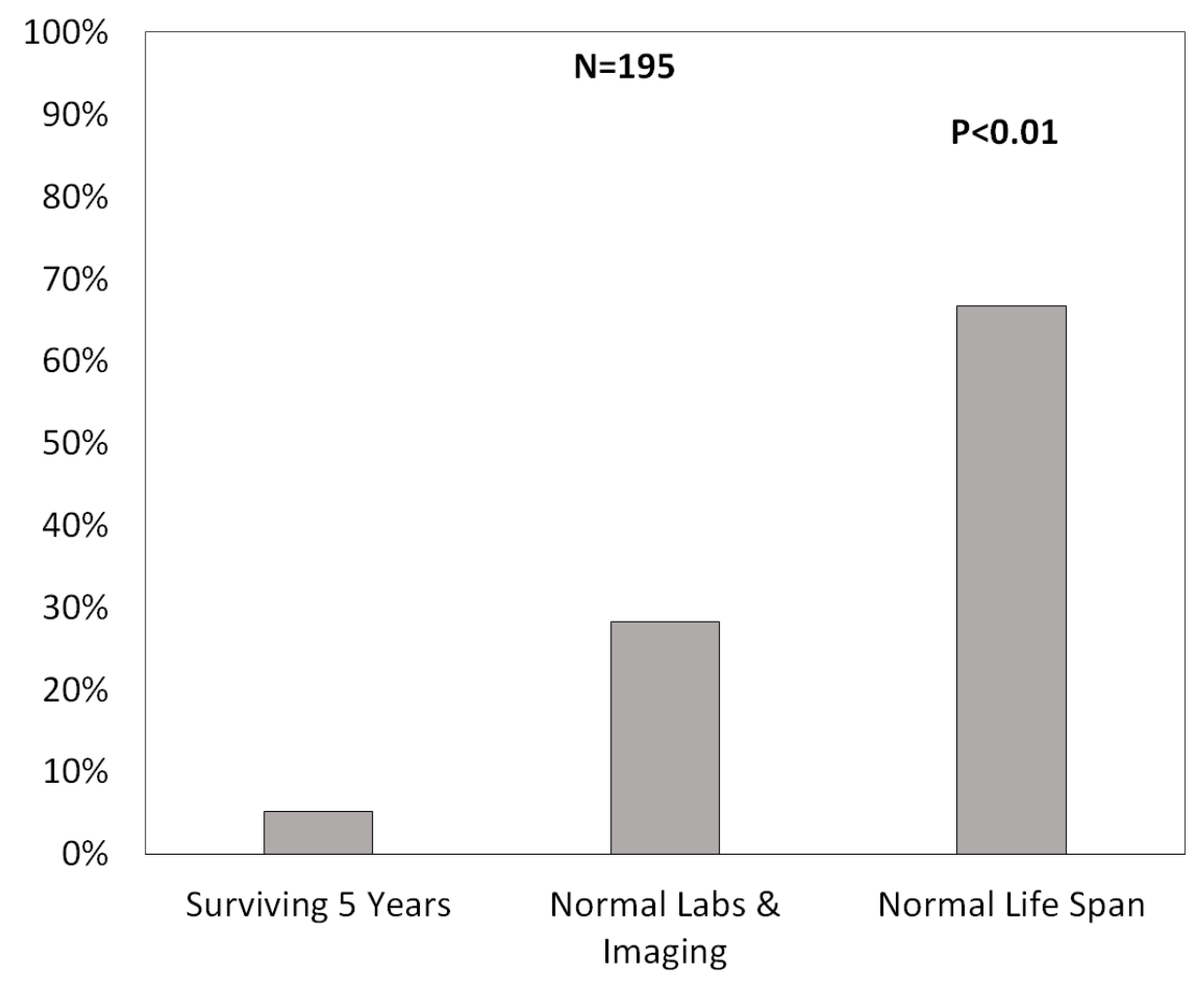


Figure 2A

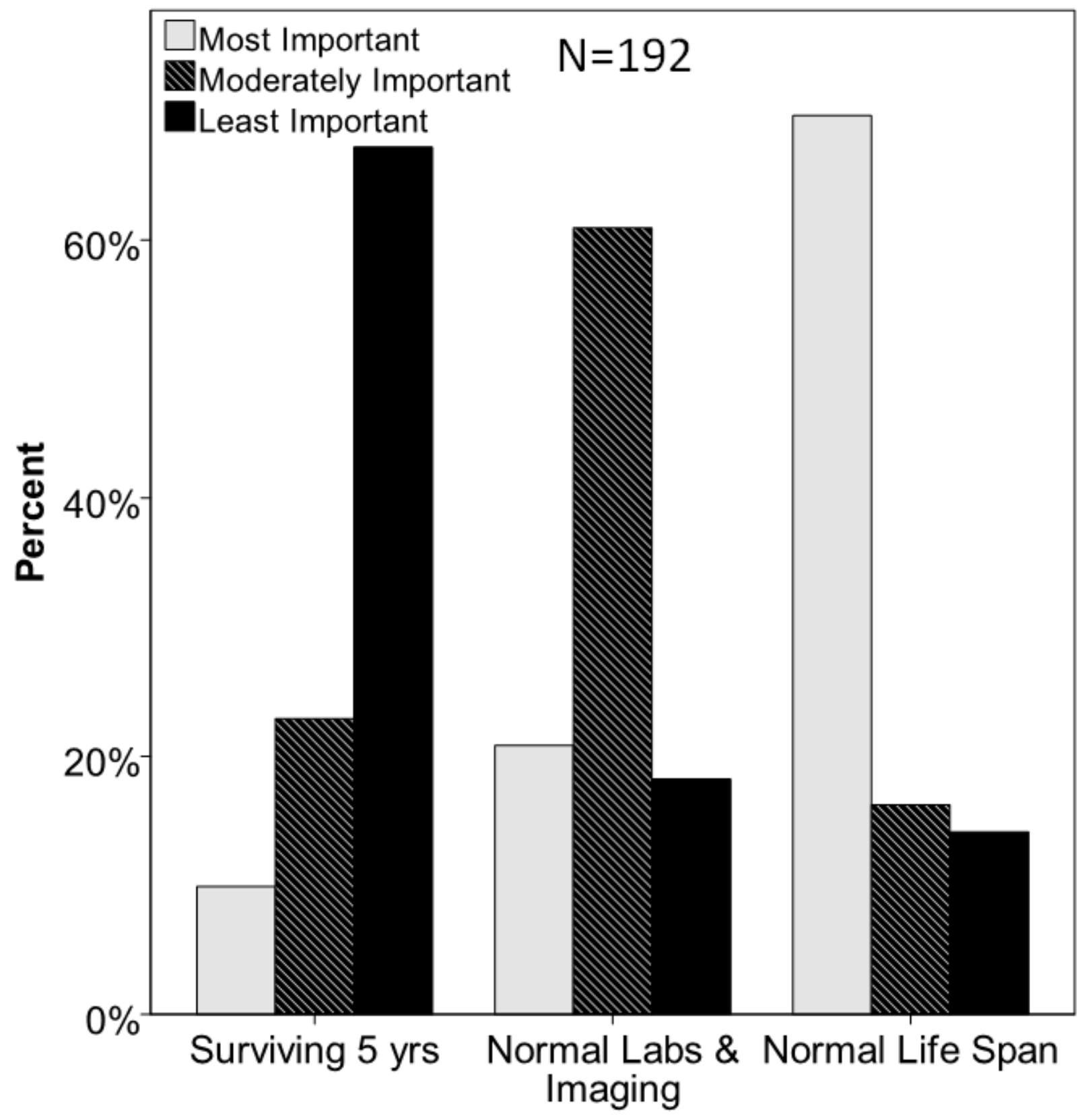


Figure 2B

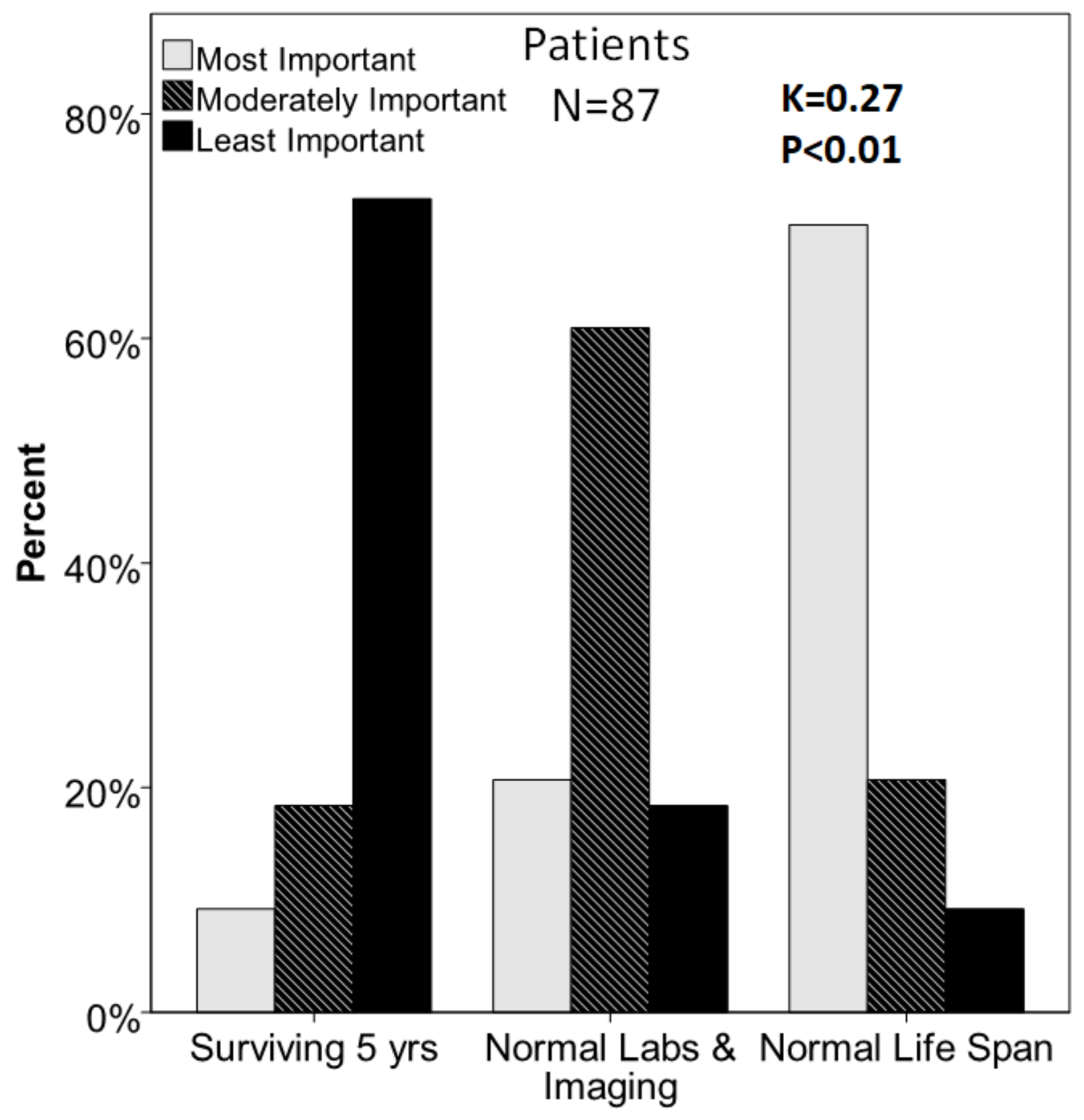


Figure $2 \mathrm{C}$

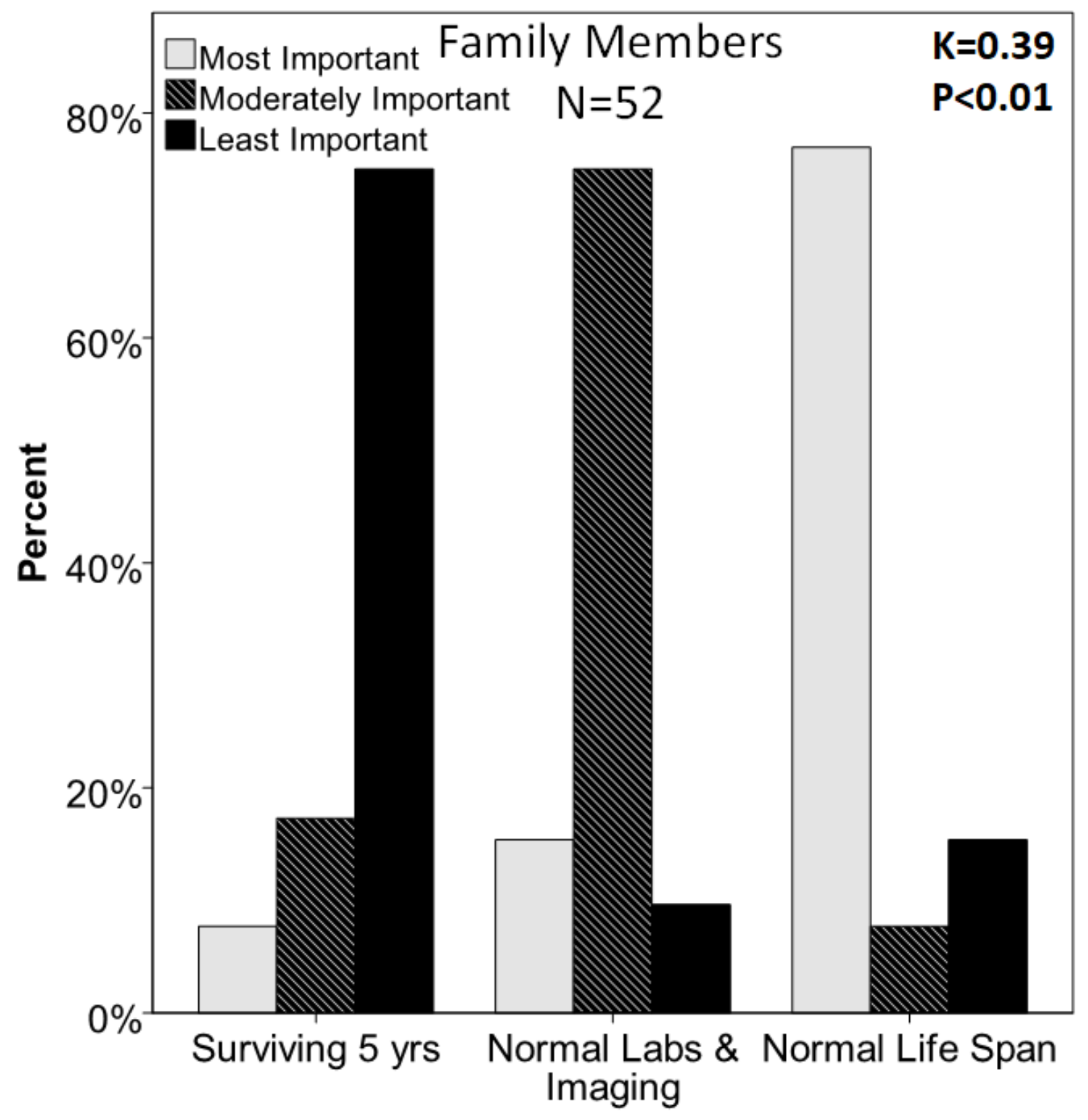


Figure 2D

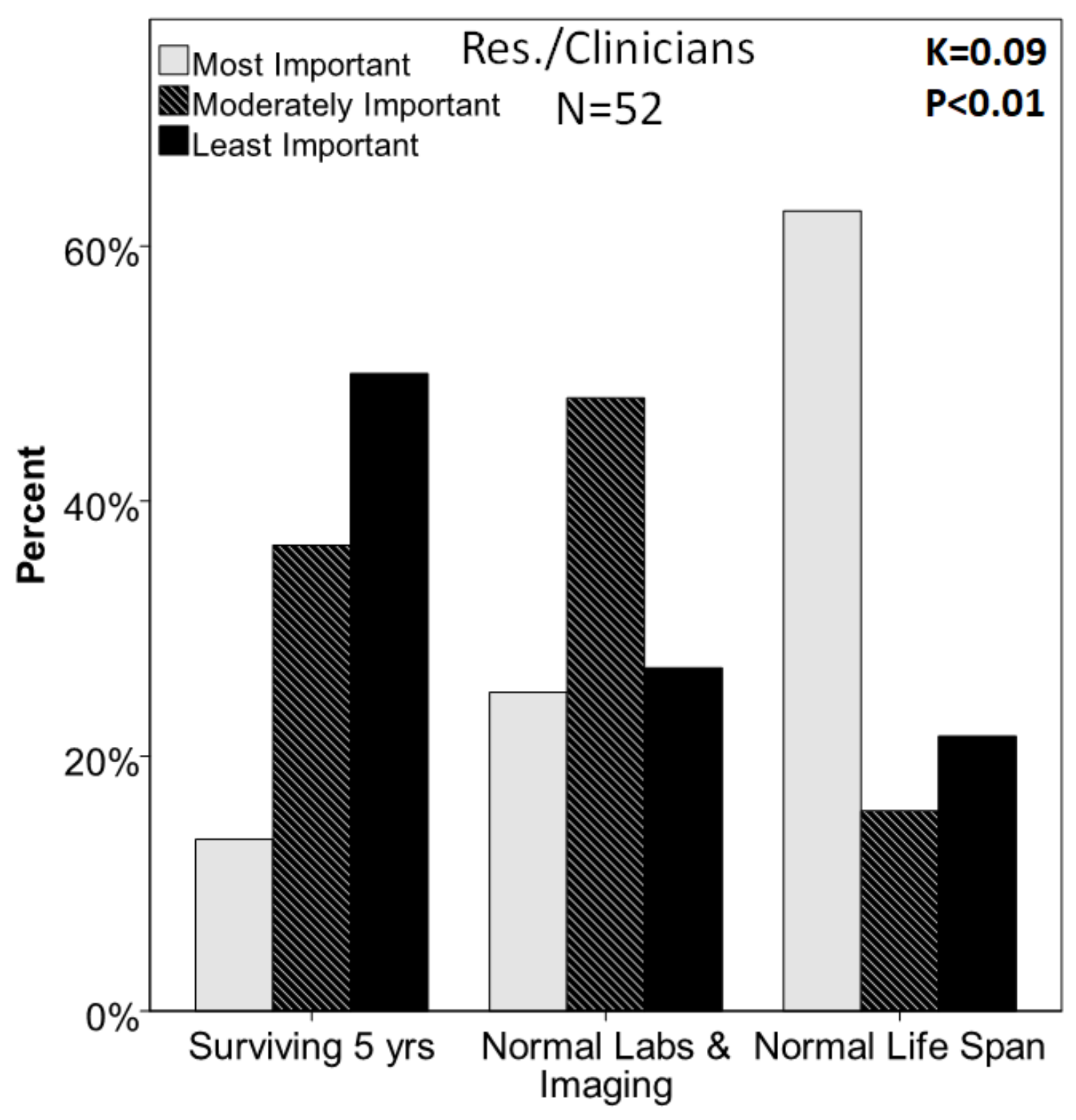

